\title{
Elastic properties of the lung and the chest wall in young and adult healthy pigs
}

\author{
E. De Robertis*,+, J.M. Liu*, S. Blomquist", P.L. Dahm", J. Thörne ${ }^{\star}$, B. Jonson\#
}

Elastic properties of the lung and the chest wall in young and adult healthy pigs. E. De Robertis, J.M. Liu, S. Blomquist, P.L. Dahm, J. Thörne, B. Jonson. (C)ERS Journals Ltd 2001

ABSTRACT: Understanding of the elastic pressure/volume $(P \mathrm{el} / V)$ curve is still limited in health and disease. The aim of the present study was to elucidate the $P$ el $/ V$ curve and elastance of the respiratory system $(E R S)$ lung $(E L)$ and chest wall $(E C W)$ in healthy pigs.

Six young $(20.8 \mathrm{~kg})$ and seven adult $(58.9 \mathrm{~kg})$, anaesthetized, paralysed and ventilated pigs were studied. $P \mathrm{el} / V$ curves were recorded at zero end-expiratory pressure (ZEEP) and at positive end-expiratory pressure (PEEP) up to $40 \mathrm{cmH}_{2} \mathrm{O}$ with a computer controlled ventilator during an insufflation at a low, constant flow.

$P \mathrm{el} / V$ curves of the respiratory system showed a complex pattern in both young and adult pigs. During the insufflation, $E$ RS decreased, increased, fell, and increased again. A second $P \mathrm{el} / V$ curve recorded immediately after the first one showed lower elastance and only one early fall in ERS. ECW fell over the initial segment and was then nearly stable. Difference between 1st and 2nd curves reflected changes in EL caused by recruitment during the 1st insufflation. At PEEP, such signs of collapse and recruitment were reduced.

A strong tendency to lung collapse contributes to a complex pattern of elastic pressure/volume curves. At low volumes and distending pressures the chest wall contributes significantly to changes in respiratory system elastance.

Eur Respir J 2001; 17: 703-711.
Depts of *Clinical Physiology, *Anesthesia and Intensive Care, and "Surgery, University Hospital of Lund, Lund, Sweden. ${ }^{+}$Dept of Anesthesia and Intensive, University "Federico II", Via S. Pansini 5, Napoli, Italy.

Correspondence: B. Jonson, Dept of Clinical Physiology, Lund University Hospital, Lund, Sweden, S-221 85 Fax: 4646151769

Keywords: Animal, elastance, mechanics, porcine, recruitment

Received: December 281999

Accepted after revision November 28 2000

This study was supported by the Swedish Medical Research Council (grants 02872), the Swedish Heart Lung Foundation, and Stiftelsen Länsförsäkringsbolagens Försäkringsfond. $\mathrm{Dr} \mathrm{De}$ Robertis was supported by a scholarship of the Swedish Institute.
The elastic pressure/volume $(P \mathrm{el} / V)$ curve has, during the last years, attracted increasing interest since it may offer guidance in setting ventilators in patients with adult respiratory distress syndrome. The interest has been focused on the lower inflexion point (LIP) of the curve and its relationship to an optimal level of positive end-expiratory pressure [1-5]. The observation of an LIP at quite high pressures in healthy man has led to discussion about the nature of the LIP. The possibility that the thoracic cage might cause an inflexion point together with or rather than recruitment of collapsed lung units has been discussed [6, 7]. Furthermore, the concept that the linear segment following the LIP represents a $P \mathrm{el} / V$ range at which the lung is well recruited has been challenged on the basis of theoretical and experimental studies [8-10].

In young healthy pigs it has been observed that the $P \mathrm{el} / V$ curve of the respiratory system showed a nonlinear and complex pattern if a recruitment manoeuvre was not performed immediately before the recording [6]. When compliance was plotted against distending pressure, two peaks were observed. This complex pattern was considered to reflect a tendency for airspace to collapse in a more pronounced fashion than in humans. The application of positive endexpiratory pressure (PEEP) of $4 \mathrm{cmH}_{2} \mathrm{O}$ only partly prevented lung collapse. It was discussed whether the behaviour of the lungs was affected by the juvenile age of the animals. Spurred by the prospect of lung xenotransplantation with a transgenic pig as donor [11] and by an interest to further explore the nature of the $P \mathrm{el} / V$ curve, the investigation was extended by partitioning respiratory system mechanics into pulmonary and chest wall components in both adult and juvenile pigs.

The constant flow insufflation technique $[5,7,12]$ was complemented with measurement of pleural pressure with the oesophageal balloon technique.

\section{Materials and methods}

The experimental protocol complied with the guidelines of the Ethics Board of Animal Research, University of Lund, Sweden. The study was performed in two groups of pigs of the Swedish land-race: six young pigs weighing $20.8 \mathrm{~kg}$ (range $18-23 \mathrm{~kg}$ ) and seven adult pigs weighing $58.9 \mathrm{~kg}$ (range $55-65 \mathrm{~kg}$ ). The age of young and adult pigs was about 12 and 24 weeks, respectively. 


\section{Animal preparation}

All pigs were fasted over night but allowed free access to water. In order to avoid stress during induction of anaesthesia, animals were premedicated with azaperone (Stresnil@; Janssen, Beerse, Belgium) $6 \mathrm{mg} \cdot \mathrm{kg}^{-1}$. Ana-

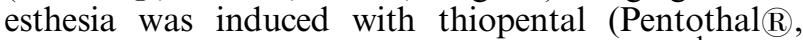
Abbott, North Chicago, IL, USA) $12.5 \mathrm{mg} \cdot \mathrm{kg}^{-1}$, given through a cannula placed into an ear vein. Young pigs were then orotracheally intubated with a Portex cuffed tube with an internal diameter (ID) of $6.5 \mathrm{~mm}$. In adult pigs a tracheotomy was performed and an ID $8.5 \mathrm{~mm}$ Portex cuffed tube inserted. The tube cuff was inflated and frequently tested to avoid air leakage. Anaesthesia and paralysis were maintained by the continuous infusion of fentanyl (Leptanal $\AA$, Janssen) $75 \mu \mathrm{g} \cdot \mathrm{kg}^{-1} \cdot \mathrm{h}^{-1}$, pancuronium bromide (Pavulon $\AA$, Organon Teknika, Boxtel, Holland) $0.45 \mathrm{mg} \cdot \mathrm{kg}^{-1} \cdot \mathrm{h}^{-1}$ and midazolam (Dormicum $\mathbb{R}$, Hoffmann-La Roche AG, Basel, Switzerland) $0.25 \mathrm{mg} \cdot \mathrm{kg}^{-1} \cdot \mathrm{h}^{-1}$

Volume controlled ventilation at constant inspiratory flow was given at 20 breaths $\cdot \mathrm{min}^{-1}$ with a Servo Ventilator $900 \mathrm{C}$ equipped with a $\mathrm{CO}_{2}$ Analyser 930 for monitoring of end-tidal $\mathrm{CO}_{2}$ (Siemens-ElemaAB, Sweden). Minute ventilation was adjusted to ensure an arterial carbon dioxide partial pressure $\left(\mathrm{Pa}, \mathrm{CO}_{2}\right)$ 4 $4.5 \mathrm{kPa}$. This resulted in a tidal volume of on average $10 \mathrm{~mL} \cdot \mathrm{kg}^{-1}$. Inspiratory time was $33 \%$ of the respiratory cycle and postinspiratory pause $5 \%$. The oxygen inspiratory fraction was 0.21 . Ventilator setting was maintained constant throughout the experiments except for change in end-expiratory pressure (PEEP) that was set at either $+4 \mathrm{cmH}_{2} \mathrm{O}$ or zero (ZEEP).

The carotid artery was cannulated on the left side for measurement of arterial blood pressure (ABP), and heart rate (HR) monitoring and arterial blood sampling. The external jugular vein on the left side was cannulated for infusion of Ringer's solution at a rate of $5 \mathrm{~mL} \cdot \mathrm{kg}^{-1} \cdot \mathrm{h}^{-1}$. Body temperature was maintained within $1{ }^{\circ} \mathrm{C}$ of baseline. After the experiment all animals were sacrificed with an overdose of potassium.

\section{Instrumentation and measurements}

Tracheal pressure $(P \operatorname{tr})$ was measured with a pressure transducer (SenSym SX01DN, Sensortec GmbH, Germany) connected to a polyethylene catheter (outer diameter $1.5 \mathrm{~mm}$, inner diameter $0.8 \mathrm{~mm}$ ). The side holes of the catheter were placed $2 \mathrm{~cm}$ beyond the tip of the tracheal tube, where effects of changing diameter of the conduit have died away.

Pleural pressure $(P \mathrm{pl})$ was measured with a pressure transducer (CD23-C, Validyne, Northridge, CA, USA) connected to an oesophageal, thin-walled, latex, $5 \mathrm{~cm}$ long balloon filled with $0.5 \mathrm{~mL}$ of air. The balloon was positioned in the distal half of the oesophagus. Adequate transmission of pleural pressure to the balloon was verified with an occlusion test. This test was performed by gentle squeezing of the chest and the abdomen whilst the airway was blocked, both after an inspiration and after an expiration.

The Servo Ventilator was connected to an IBM compatible personal computer through a ventilator/ computer interface, as has previously been described [5, $7,12]$. The computer emitted analogue signals which, when fed to the external control socket of the ventilator, allowed the computer to take over control of respiratory frequency, PEEP, and minute ventilation. Flow and total expiratory pressure were recorded using the flow and expiratory pressure transducers of the ventilator. The latter, together with $P \operatorname{tr}$ and $P$ pl transducers, were calibrated daily against a $1-\mathrm{L}$ syringe and a water manometer. Flow and volume were calibrated to yield data at body temperature and pressure, saturated with water vapour (BTPS).

Signals of total expiratory pressure, $P \operatorname{tr}, P \mathrm{pl}$ and flow were fed to the ventilator/computer interface and filtered to avoid aliasing, and then to the computer for analogue/digital conversion at $50 \mathrm{~Hz}$. Airway flow was calculated by correcting the measured flow rate for gas compression in tubings. Volume $(V)$ was then calculated by integration of flow. During the procedure, the computer continuously recorded pressures and flow. These data were automatically transferred to a spreadsheet prepared so that analysis and data presentation were automatically performed.

\section{Recording and analysis of $\mathrm{Pel} / \mathrm{V}$ curves}

$P \operatorname{tr} / V$ and $P \mathrm{pl} / V$ curves were recorded during one single insufflation at constant flow. After a first normal complete breath and a second normal inspiration, the following expiration was prolonged to $6 \mathrm{~s}$ to allow for complete flow cessation. The duration of the following inspiratory phase, denoted the insufflation, was prolonged to $6 \mathrm{~s}$. The computer controlled the flow during insufflation so that the volume reached on average 62 and $43 \mathrm{~mL} \cdot \mathrm{kg}^{-1}$ during the $6 \mathrm{~s}$ in young and adult pigs, respectively. This insufflated volume ( $V$ insuff) was chosen so as to result in a peak pressure covering $40 \mathrm{cmH}_{2} \mathrm{O}$ in each group of pigs. The average flow during the insufflation in young and adult pigs was 214 and $416 \mathrm{~mL} \cdot \mathrm{s}^{-1}$, respectively. As the system does not permit a longer insufflation time than $6 \mathrm{~s}$, these flows were the lowest possible allowing a pressure of 40 $\mathrm{cmH}_{2} \mathrm{O}$ to be reached. During a prolonged expiration following the insufflation, lung volume was allowed to return to baseline ZEEP or PEEP level.

The resistance within the respiratory system was determined from the complete unperturbed breath preceding the insufflation according to VARÈNE and JAQUEMIN [13]. The sum of flow values multiplied by $P \operatorname{tr}$ was divided by the sum of squared flow values. This so called "effective resistance" has previously been used for calculation of $P \mathrm{el}[5,7,10]$. The resistance within the thoracic cage was similarly calculated on the basis of $P$ pl. The resistive pressure gradient within the respiratory system and the thoracic cage was then calculated from flow during insufflation, and subtracted from $P \operatorname{tr}$ and $P$ pl to obtain the dynamic elastic recoil pressure of the respiratory system and the thoracic wall, $P$ el,RS and $P$ el,CW, respectively. The difference between $P$ el, RS and $P$ el,CW, constitutes the dynamic elastic recoil pressure of the lung $(P \mathrm{el}, \mathrm{L})$.

Compliance, at each point of the $P$ el, RS $/ V$ and $P$ el,CW/ $V$ curves was obtained by a moving regression 
[6]. One objective of this study was partitioning of the elastic properties of the respiratory system into the chest wall and lung components. Since the elastance of the respiratory system is the sum of chest wall and lung elastance the data has been presented in terms of elastance rather than compliance. Likewise, as the $P$ el,RS is the sum of $P$ el, L and $P$ el, CW,$P$ el $/ V$ diagrams were presented with the volume on the $\mathrm{x}$-axis.

Elastance $(E)$ was calculated as the reciprocal of compliance. As pigs of different size were compared E was normalized by multiplying by body weight. This is in analogy with the more common normalization of compliance by dividing compliance by body weight. Accordingly, $E$ is expressed in $\mathrm{cmH}_{2} \mathrm{O} \cdot \mathrm{mL}^{-1} \cdot \mathrm{kg}$. Elastance of the lung (EL) was calculated as the difference between elastance of respiratory system (ERS) and elastance of chest wall (ECW). Then, ERS, ECW and $E \mathrm{~L}$ were plotted versus $P$ el,RS resulting in $P$ el,RS/ERS, $P$ el, RS/ECW, and $P$ el, RS/EL curves. Pel,RS, i.e. the distending pressure of the respiratory system, was used as a parameter expressing the degree of lung inflation, since this measure is independent of age and size of the pigs.

\section{Protocol}

After the preparation of the pigs, a stabilization period of $45 \mathrm{~min}$ was allowed. Then a recruitment manoeuvre was performed by inflating the lungs with a pressure of $30 \mathrm{cmH}_{2} \mathrm{O}$ for $15 \mathrm{~s}$ to eliminate atelectasis and standardize lung volume history and conditions between animals. Data acquisition started $\sim 5$ min after the recruitment manoeuvre. Data were acquired at three stages: stage I, supine position at ZEEP; stage II, left lateral position at ZEEP; stage III, left lateral position at a PEEP of $4 \mathrm{cmH}_{2} \mathrm{O}$. At each stage, haemodynamic data were collected. Then two $P$ el $/ V$ recordings were performed. About $20 \mathrm{~s}$ elapsed between the first and the second recordings. After stage $I$, the position was changed and after stage II, PEEP was set. Thirty minutes were allowed for stabilization at the new conditions. Data of stages II and III are presented.

\section{Statistical analysis}

Data are expressed as mean \pm SD. To study elastance in relation to pressure, analysis of variance (ANOVA) was used. For pair-wise comparisons, the two tailed ttest was used. Differences were considered significant at a $p$-value of $p \leqslant 0.05$

\section{Results}

After sacrifice, a macroscopic inspection of the lungs was made in all pigs except in two young ones. One adult pig was excluded because of hypoxaemia, tachycardia and visual evidence of pneumonia. Other inspected lungs had normal appearance. The 12 pigs accepted for evaluation had normal baseline haemodynamics and blood gases (heart rate: $85.8 \pm 22$ beats. $\mathrm{min}^{-1}$; mean arterial blood pressure: $79.2 \pm 15 \mathrm{mmHg}$;
$\left.P \mathrm{a}, \mathrm{O}_{2}: 12.7 \pm 1.6 \mathrm{kPa} ; P_{\mathrm{a}}, \mathrm{CO}_{2}: 4.9 \pm 0.6 \mathrm{kPa}\right)$. These variables remained stable through the experimental period.

In the two recordings at ZEEP and at PEEP in young pigs, the average resistance of the respiratory system was in the range $3.9-4.5 \mathrm{cmH}_{2} \mathrm{O} \cdot \mathrm{L}^{-1} \cdot \mathrm{s}$. The resistive pressure subtracted to obtain $P$ el,RS was about 0.9 $1.0 \mathrm{cmH}_{2} \mathrm{O}$. In adult pigs, the corresponding resistance values were $1.1-1.4 \mathrm{cmH}_{2} \mathrm{O} \cdot \mathrm{L}^{-1} \cdot \mathrm{s}$ and the subtracted resistive pressure $0.7-0.8 \mathrm{cmH}_{2} \mathrm{O}$.

First elastic pressure/volume recording at zero endexpiratory pressure

The 1 st $P$ el, RS/ $V$ curve at ZEEP in adult pigs showed the same complex features as previously reported in young pigs (fig. 1) [6]. ERS varied significantly with pressure $(\mathrm{p}<0.01)$. Figure 2 illustrates how ERS first fell, then increased, then fell again in each adult pig. At the highest elastic recoil pressures, ERS finally increased. Small pigs showed the same consistent features.

$E C W$ fell within the $P$ el, RS range from 5-20 $\mathrm{cmH}_{2} \mathrm{O}$ in each young and adult pig (ANOVA $\mathrm{p}<0.05$ ). Paired comparison showed that this fall was significant in each group $(\mathrm{p}<0.01)$. At higher degrees of distension, ECW stabilized or increased again (tables 1 and 2, fig. 3).
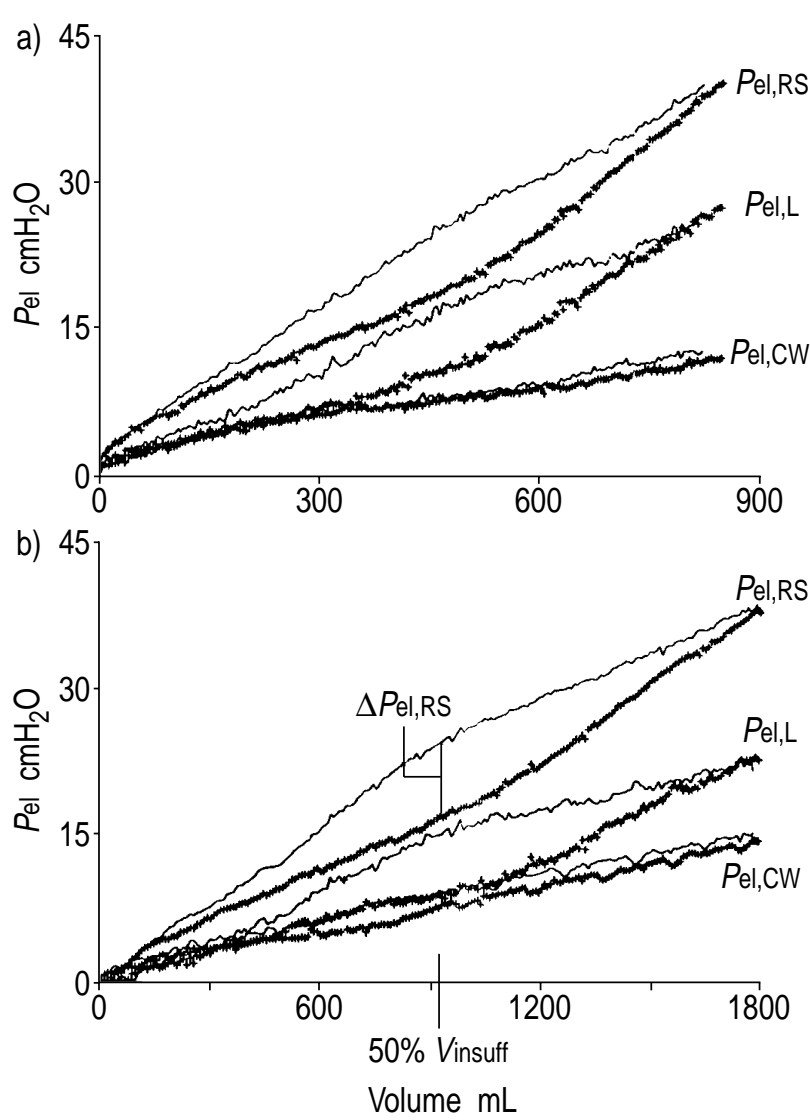

Fig. 1. - a) Young and b) adult representative pigs. $P$ el $/ V$ curves of the respiratory system $(P \mathrm{el}, \mathrm{RS})$, lung $(P \mathrm{el}, \mathrm{L})$, and chest wall $(P \mathrm{el}, \mathrm{CW})$, during the 1 st $(-)$ and 2 nd $(+++)$ recordings. The difference in $P$ el, RS ( $\triangle P$ el,Rs) between the 1 st and 2 nd recordings at a volume equal to $50 \%$ of the insufflated volume ( $V$ insuff) is indicated. 

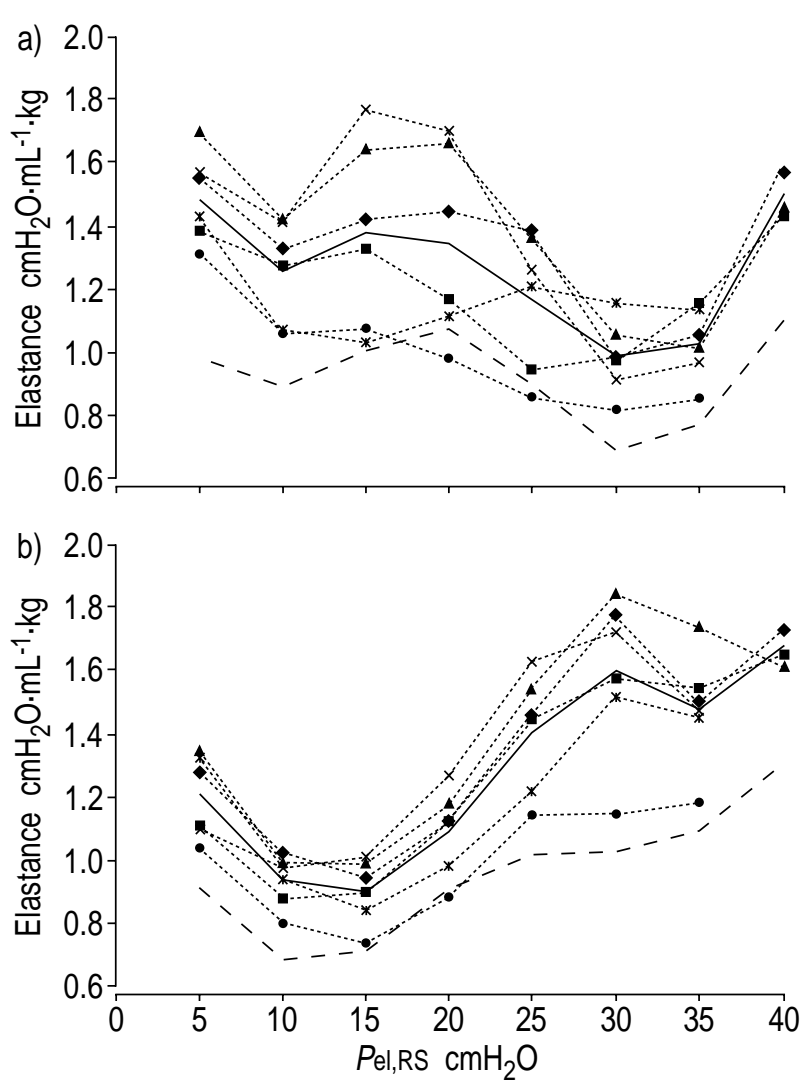

Fig. 2. - a) 1st and b) 2nd recordings at zero end-expiratory pressure (ZEEP); behaviour of the elastance of the respiratory system (ERS) at increasing pressures. - : mean adult values; - -: mean young values; …... individual adult pigs.

Elastance of the lung showed similar principle features as ERS except that an initial fall was not observed. Accordingly, the chest wall caused the initial fall of $E$ RS. The increase of ERS over the range of resistances 10-20 $\mathrm{cmH}_{2} \mathrm{O}$, and the following decrease, as resistance increased to $30 \mathrm{cmH}_{2} \mathrm{O}$, reflected properties of the lung. Both the lung and the chest wall contributed to the final increase in ERS (tables 1 and 2, and fig. 3).
Second elastic pressurelvolume recording at zero endexpiratory pressure

The secnd $P \mathrm{el} / V$ recording at ZEEP showed, fewer complex features than the first recording, which was performed $20 \mathrm{~s}$ earlier, in adults pigs as well as in young pigs, (figs. 1 and 2). ERS varied significantly with pressure $(\mathrm{p}<0.001)$. In the 2 nd $P$ el, RS $/ V$ recording, ERS decreased over the segment as resistance increased up to $10 \mathrm{cmH}_{2} \mathrm{O}$. Then, over the segment 15-30 $\mathrm{cmH}_{2} \mathrm{O}$, ERS increased to reach nearly constant values (figs. 2 and 3 ). The initial fall of ERS reflected corresponding changes in $E \mathrm{CW}$, which fell within the $P$ el, RS range 5-20 $\mathrm{cmH}_{2} \mathrm{O}$ in young and adult pigs (ANOVA $\mathrm{p}<0.01$ ). Paired comparison showed that this fall in ECW was significant in the second recording $(\mathrm{p}<0.05)$, as it was in the first. The subsequent larger increase in ERS was due to the lung. Above $30 \mathrm{cmH}_{2} \mathrm{O}, E \mathrm{CW}$ and $E \mathrm{~L}$ showed minor changes (tables 1 and 2, and fig. 2).

In the combined group of young and adult pigs, the difference in $P$ el between the 1 st and the 2 nd recordings at a volume equal to $50 \%$ of the insufflated volume, $\Delta P$ el, was measured as shown in figure $1 . \Delta P$ el for the respiratory system, the lung and the chest wall differed significantly from zero, both at PEEP and ZEEP (table 3). At ZEEP, $76 \%$ of $\Delta P$ el, RS reflected the lung. At PEEP $\Delta P \mathrm{el}, \mathrm{RS}$ and $\Delta P \mathrm{el}, \mathrm{L}$ were significantly lower than at ZEEP.

Elastic pressurelvolume recordings at positive endexpiratory pressure

At PEEP, the first and the second recordings in young and adult pigs showed a steady increase in ERS up to a $P$ el, RS of about $25-35 \mathrm{cmH}_{2} \mathrm{O}$. At the highest pressures ERS was nearly stable. This pattern of ERS reflected the elastance of the lungs, as ECW was nearly stable over the full range of $P$ el,RS (tables 1 and 2, and fig. 4). A consequence of this pattern is that in the combined group of pigs, the fraction of ERS caused by the chest wall fell from 0.54 at the pressure interval $10-15 \mathrm{cmH}_{2} \mathrm{O}$ to 0.26 over the pressure interval 35-40 $\mathrm{cmH}_{2} \mathrm{O}$.

Table 1. - Respiratory system, lung, and chest wall elastance at increasing elastic recoil pressure in young pigs

\begin{tabular}{|c|c|c|c|c|c|c|c|c|c|c|c|c|}
\hline \multirow{3}{*}{$\begin{array}{l}P \mathrm{el}, \mathrm{RS} \\
\mathrm{cmH}_{2} \mathrm{O}\end{array}$} & \multicolumn{6}{|c|}{ ZEEP } & \multicolumn{6}{|c|}{ PEEP } \\
\hline & \multicolumn{2}{|c|}{ ERS } & \multicolumn{2}{|c|}{$E \mathrm{~L}$} & \multicolumn{2}{|c|}{$E \mathrm{CW}$} & \multicolumn{2}{|c|}{ ERS } & \multicolumn{2}{|c|}{$E \mathrm{~L}$} & \multicolumn{2}{|c|}{$E \mathrm{CW}$} \\
\hline & 1 & 2 & 1 & 2 & 1 & 2 & 1 & 2 & 1 & 2 & 1 & 2 \\
\hline 5 & 0.98 & 0.89 & 0.45 & 0.37 & 0.52 & 0.51 & & & & & & \\
\hline 10 & $0.89 *$ & 0.67 & 0.47 & 0.32 & $0.42 *$ & 0.34 & $0.64^{(*)}$ & 0.61 & 0.25 & 0.28 & $0.39 *$ & 0.33 \\
\hline 15 & $1.01 *$ & 0.71 & 0.65 & 0.43 & 0.35 & 0.27 & $0.74 * * *$ & 0.61 & $0.38 * *$ & 0.32 & $0.35^{* *}$ & 0.29 \\
\hline 20 & $1.08^{*}$ & 0.91 & 0.77 & 0.57 & 0.30 & 0.33 & 0.89 & 0.79 & 0.57 & 0.50 & 0.32 & 0.30 \\
\hline 25 & 0.91 & 1.02 & 0.52 & 0.58 & 0.39 & 0.43 & $1.13^{(*)}$ & 1.09 & $0.82^{(*)}$ & 0.66 & 0.31 & 0.43 \\
\hline 30 & $0.71 * * *$ & 1.03 & $0.38 *$ & 0.62 & 0.33 & 0.41 & $1.22 * * *(* * *)$ & $1.45^{(* *)}$ & $0.76^{(*)}$ & $1.06^{(*)}$ & $0.45^{(*)}$ & 0.39 \\
\hline 35 & $0.78 * *$ & 1.10 & $0.43 *$ & 0.71 & 0.34 & 0.38 & $1.23 * * *(* *)$ & $1.65^{(* * *)}$ & $0.76 * * *(*)$ & $1.17^{(* * *)}$ & 0.47 & 0.48 \\
\hline 40 & $1.12 *$ & 1.31 & 0.63 & 0.70 & 0.48 & 0.60 & $1.37^{(*)}$ & $1.60^{(*)}$ & $0.82 *$ & $1.13^{(*)}$ & $0.55^{*}$ & 0.47 \\
\hline
\end{tabular}

Data are presented as means and elastance units are $\mathrm{cmH}_{2} \mathrm{O} \cdot \mathrm{mL}^{-1} \cdot \mathrm{kg}$. ZEEP: zero end-expiratory pressure; PEEP: positive end-expiratory pressure; $E \mathrm{RS}, E \mathrm{~L}$, and $E \mathrm{CW}$ : respiratory system, lung, and chest wall elastance, respectively; $P$ el,RS: respiratory system elastic recoil pressure; 1: first recording; 2: second recording. p-values are reported as difference between first and second recordings (difference between corresponding ZEEP and PEEP recordings). *: $\mathrm{p}<0.05 ; * *: \mathrm{p}<0.01 ; * * *: \mathrm{p}<0.001$. 
Table 2. - Respiratory system, lung, and chest wall elastance at increasing elastic recoil pressure in adult pigs

\begin{tabular}{|c|c|c|c|c|c|c|c|c|c|c|c|c|}
\hline \multirow{3}{*}{$\begin{array}{l}P \mathrm{el}, \mathrm{RS} \\
\mathrm{cmH}_{2} \mathrm{O}\end{array}$} & \multicolumn{6}{|c|}{ ZEEP } & \multicolumn{6}{|c|}{ PEEP } \\
\hline & \multicolumn{2}{|c|}{ ERS } & \multicolumn{2}{|c|}{$E \mathrm{~L}$} & \multicolumn{2}{|c|}{$E \mathrm{CW}$} & \multicolumn{2}{|c|}{$E$ RS } & \multicolumn{2}{|c|}{$E \mathrm{~L}$} & \multicolumn{2}{|c|}{$E \mathrm{CW}$} \\
\hline & 1 & 2 & 1 & 2 & 1 & 2 & 1 & 2 & 1 & 2 & 1 & 2 \\
\hline 5 & $1.49^{* *}$ & 1.20 & $0.60 *$ & 0.45 & $0.89^{*}$ & 0.75 & & & & & & \\
\hline 10 & $1.26^{* * *}$ & 0.93 & $0.57 *$ & 0.39 & $0.69 * * *$ & 0.54 & $1.04 * *(* *)$ & 0.93 & $0.46^{*}$ & 0.38 & $0.58^{(*)}$ & 0.54 \\
\hline 15 & $1.38^{* *}$ & 0.90 & $0.70 *$ & 0.36 & 0.68 & 0.54 & $1.13 * *(*)$ & 0.90 & $0.52 * *$ & 0.38 & $0.61 *$ & 0.52 \\
\hline 20 & $1.35^{*}$ & 1.10 & $0.76^{*}$ & 0.61 & $0.59 *$ & 0.48 & $1.34 * *$ & $1.04^{(* *)}$ & $0.76^{*}$ & $0.58^{(*)}$ & $0.58 * *$ & 0.46 \\
\hline 25 & $1.18 *$ & 1.41 & $0.73 *$ & 0.91 & 0.46 & 0.50 & $1.50 *(* *)$ & 1.36 & $0.99^{(* * *)}$ & $0.90^{(*)}$ & 0.51 & 0.46 \\
\hline 30 & $1.00^{* *}$ & 1.61 & $0.57 * * *$ & 1.11 & 0.42 & 0.50 & $1.48 * *(* *)$ & $1.82^{(* * *)}$ & $1.01 * *(* * *)$ & $1.32^{(* * *)}$ & 0.46 & 0.50 \\
\hline 35 & $1.05^{* * *}$ & 1.49 & $0.55 * * *$ & 1.00 & 0.50 & 0.49 & $1.36 * *(*)$ & $2.16^{(* * *)}$ & $0.85 * *(*)$ & $1.64^{(* * *)}$ & 0.51 & 0.51 \\
\hline 40 & & & & & & & $1.62 * *$ & $2.21^{(* *)}$ & $0.87 * *$ & $1.63^{(* *)}$ & $0.75^{*}$ & 0.56 \\
\hline
\end{tabular}

Data are presented as means and elastance units are $\mathrm{cmH}_{2} \mathrm{O} \cdot \mathrm{mL}^{-1} \cdot \mathrm{kg}$. ZEEP: zero end-expiratory pressure; PEEP: positive end-expiratory pressure; $E \mathrm{RS}, E \mathrm{~L}$, and $E \mathrm{CW}$ : respiratory system, lung, and chest wall elastance, respectively; $P$ el,RS: respiratory system elastic recoil pressure; 1: first recording; 2: second recording. p-values are reported as difference between first and second recordings (difference between corresponding ZEEP and PEEP recordings). *: $\mathrm{p}<0.05$; **: $\mathrm{p}<0.01 ;{ }^{* * *}: \mathrm{p}<0.001$.

a) 2
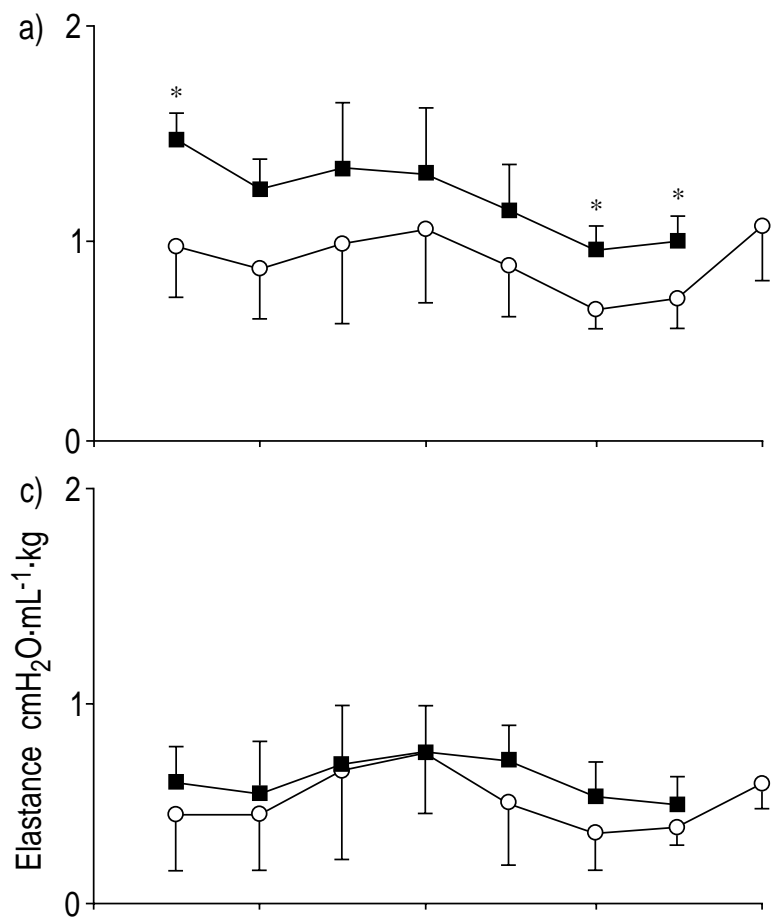

e)

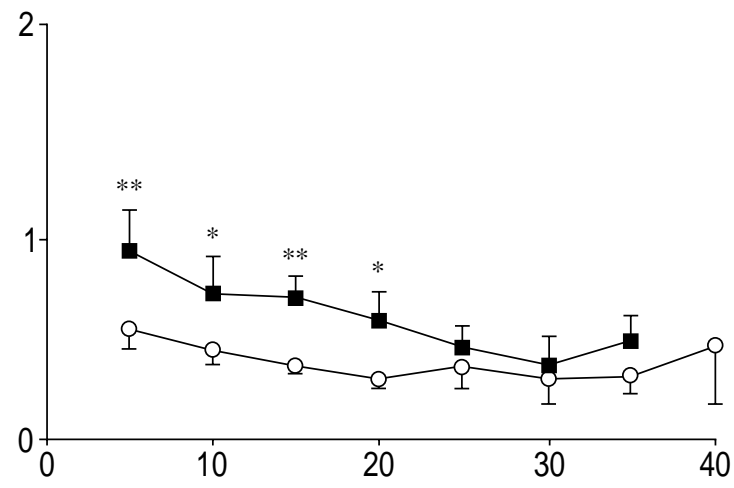

b)

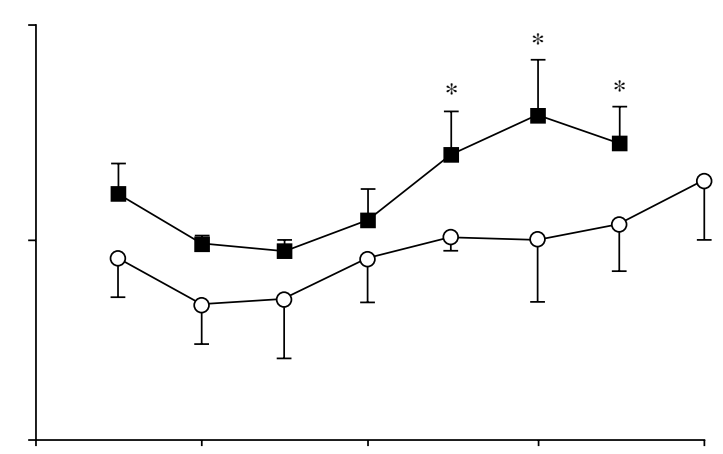

d)

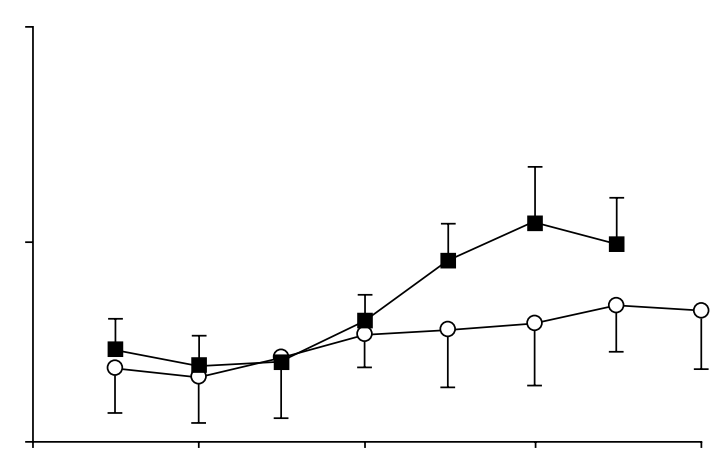

f) 2

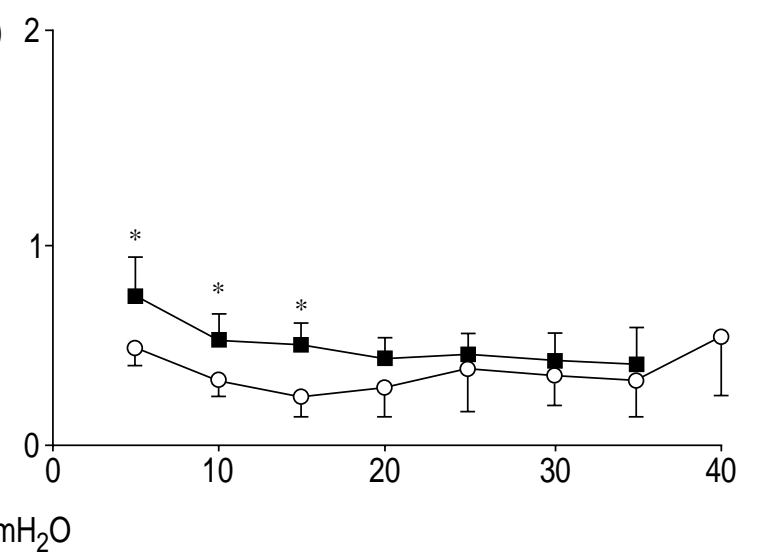

Fig. 3. - a, c, e) first and b, d, f) second recordings zero end-expiratory pressure (ZEEP) in young ( $\bigcirc)$ and adult pigs ( $\mathbf{\square})$; mean values and SDs of a, b) respiratory system $(E \mathrm{RS}), \mathrm{c}, \mathrm{d})$ lung $(E \mathrm{~L})$, and e, f) chest wall $(E \mathrm{CW})$ at increasing distending pressures $(P$ el, RS). Differences between young and adult pigs. *: $\mathrm{p}<0.05 ; * *: \mathrm{p}<0.001$. 
Table 3. - Difference in elastic recoil pressure between the first and second recordings at a volume equal to $50 \%$ of the insufflated volume

\begin{tabular}{|c|c|c|c|}
\hline & $\begin{array}{l}\Delta P_{\mathrm{el}, \mathrm{RS}} \\
\mathrm{cmH}_{2} \mathrm{O}\end{array}$ & $\begin{array}{c}\Delta P_{\mathrm{el}, \mathrm{L}} \\
\mathrm{cmH}_{2} \mathrm{O}\end{array}$ & $\begin{array}{l}\Delta P \text { el, CW } \\
\mathrm{cmH}_{2} \mathrm{O}\end{array}$ \\
\hline ZEEP & $4.8 * * *$ & $3.6^{* * *}$ & $1.1^{* *}$ \\
\hline PEEP & $1.7 * * *(* *)$ & $0.7 * *$ & $1.0 * * *$ \\
\hline
\end{tabular}

$\Delta P \mathrm{el}, \mathrm{RS}, \Delta P \mathrm{el}, \mathrm{L}, \Delta P \mathrm{el}, \mathrm{CW}$ : respiratory system; lung, and chest wall difference in elastic recoil pressure, respectively. ZEEP: zero end-expiratory pressure; PEEP: positive end-expiratory pressure. $p$-values are presented as difference from zero (difference between ZEEP and PEEP). **: $\mathrm{p}<0.05$; ***: $\mathrm{p}<0.001$.

ERS at PEEP was similar to the values observed at ZEEP up to a $P$ el,RS of $\sim 20 \mathrm{cmH}_{2} \mathrm{O}$. At higher pres-
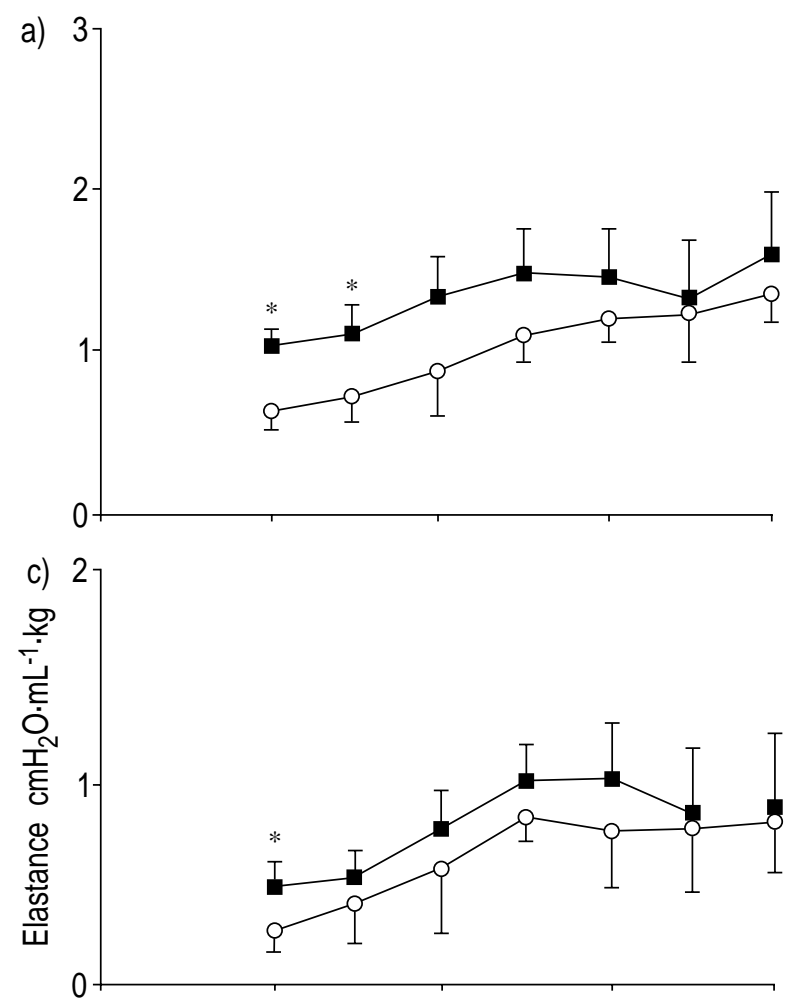

e)

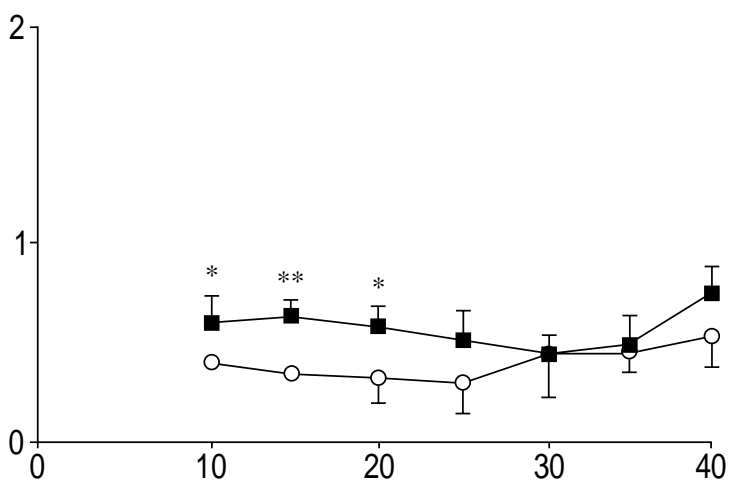

sures, ERS was significantly higher at PEEP in young and in adult pigs, both in the first and in the second recordings. The lungs caused this difference, since $E C W$ was similar at PEEP and at ZEEP (tables 1 and 2).

\section{Young versus adult pigs}

Young pigs had, in the first and second $P \mathrm{el} / V$ recordings, both at ZEEP and PEEP, a lower ERS normalized for body weight over the full pressure range. The difference was particularly significant during the 2nd recording at PEEP (fig. 4). Up to a Pel,RS of 15$20 \mathrm{cmH}_{2} \mathrm{O}$, the lower ERS in young pigs reflected that ECW was significantly lower. Over the higher range of $P$ el,RS the difference was due to the lung, although most observed differences were not significant (figs. 3 and 4).

b)

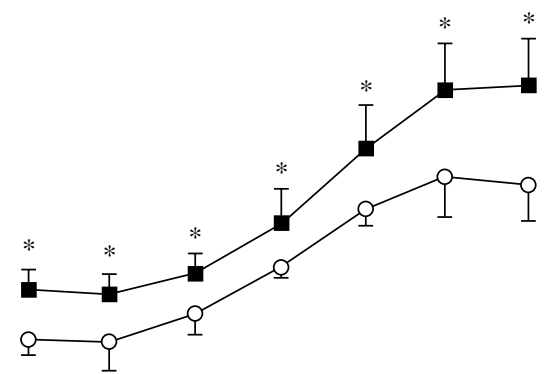

d)

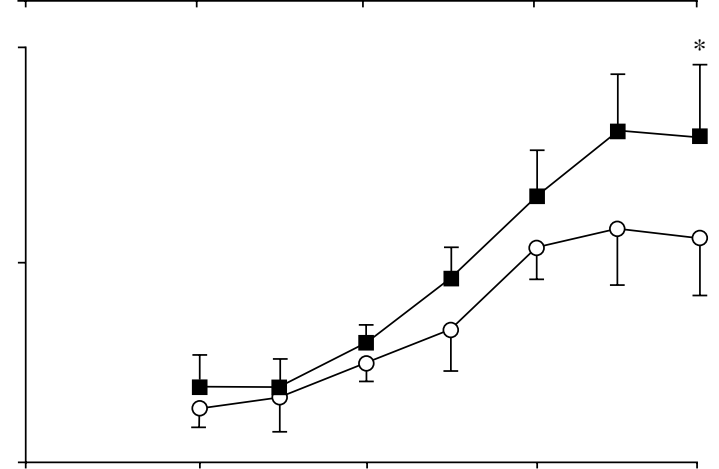

f)

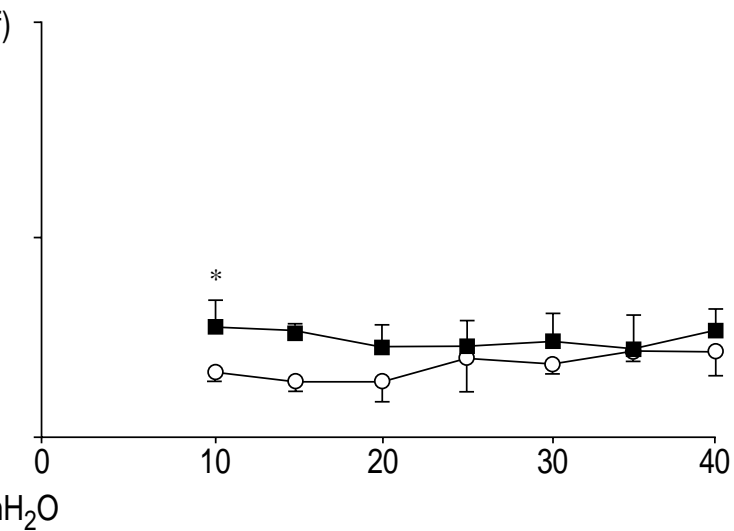

Fig. 4. - a, c, e) first and b, d, f) second recordings at positive end-expiratory pressure (PEEP) in young ( $\bigcirc)$ and adult pigs ( $\square$ ); mean values and SDs of a, b) respiratory system $(E \mathrm{RS}), \mathrm{c}, \mathrm{d})$ lung $(E \mathrm{~L})$, and e, f) chest wall $(E \mathrm{CW})$ at increasing distending pressures $(P \mathrm{el}, \mathrm{RS})$. Differences between young and adult pigs. *: $\mathrm{p}<0.05 ; * *: \mathrm{p}<0.001$. 


\section{Discussion}

In anaesthetized rabbits BERNSTEIN [14] reported as early as 1957 "extremely complex" $P \mathrm{el} / V$ curves. A second recording gave a less complex sigmoid cune. This finding was interpreted as an adaptation to insufflation. The methodology in those days offered limited possibilities to further explore the mechanisms. The present method allows a precise control of the $P \mathrm{el} /$ $V$ recording and a detailed mathematical analysis [5, 7]. The method has allowed studies showing that the physiology behind the $P$ el, RS/ $V$ curve is more complex than previously realised. For instance, in patients ventilated with PEEP because of acute lung injury, a $P$ el,RS/ $V$ curve recorded after a single expiration at ZEEP differed greatly from a curve recorded from PEEP because of lung collapse at ZEEP and recruitment during the following insufflation [10]. In healthy anaesthetized man, a similar but much less pronounced phenomenon occurs [7]. In young pigs, $P$ el,RS/ $V$ curves as complex as those in BERNSTEIN's rabbits were considered to mainly reflect a strong tendency to lung collapse and recruitment during the insufflation [6]. The importance of the age of the pig and the influence of the chest wall needed to be investigated.

In order to partition ERS between the chest wall and the lung, the pleural pressure was estimated from oesophageal pressure measurements. The occlusion test showed a proper transmission of pleural pressure to oesophagus both after expiration and inspiration. This was probably facilitated by the lateral position in which the weight of the mediastinal contents, particularly the heart, is unloaded from the pressure measurement site $[15,16]$. In young pigs it was shown that mechanics of the respiratory system were similar in the supine and the left lateral positions [6].

Because of moderate flow rates during insufflation and low resistance values of the respiratory system and the chest wall, the calculated resistive pressure, which was subtracted from tracheal and pleural pressure to obtain $P$ el, was consistently $\leqslant 1 \mathrm{cmH}_{2} \mathrm{O}$. Therefore, errors in the determination of resistance are considered not to influence the results significantly.

The continuous flow during insufflations implied that $P \mathrm{el} / V$ curves should not be regarded as static. Viscoelastic recoil will contribute to $P$ el. At constant inspiratory flow viscoelastic recoil pressure will build up until it stabilises at a constant level [17]. The time for this establishment depends upon the viscoelastic time constant of the respiratory system, which in man and dogs is about $1 \mathrm{~s}[18,19]$, but unknown in pigs. The viscoelastic time constant was equally long for lung and the thoracic wall in dogs [19]. Assuming that the viscoelastic time constant is about $1 \mathrm{~s}$, viscoelastic properties would contribute to elastance mainly during the first second of insufflation. Under no circumstances was a particularly high value of pulmonary elastance observed over the initial segment of the $P \mathrm{el} / V$ curve. The chest wall elastance was higher initially, but only at ZEEP conditions. In a previous study in young pigs, it was found that static and dynamic $P$ el $/ V$ curves were nearly similar over their initial and middle segments [6]. Combined with the present data it appears likely that viscoelastic recoil is of little importance over initial and middle segments of the $P \mathrm{el} / V$ curves.

In rabbits, the viscoelastic property of the respiratory system increases dramatically at high degrees of distension. This nonlinearity leads to a rapid increase of viscoelastic recoil pressure toward the end of forceful lung inflations [20]. Such phenomena may explain significant differences between static and dynamic elastic recoil of the respiratory system, which have been observed in man in adult respiratory distress syndrome [5], in rabbits [20] and in young pigs [6]. The dynamic character of the present $P \mathrm{el} / V$ curves implied an influence of viscoelasticity, which was probably slight over an initial segment and more important toward the very end.

The $P \mathrm{el} / V$ curves displayed a similar pattern in young and adult pigs. The hypothesis that the juvenile age might explain previous results was accordingly rejected. The main difference between young and adult pigs was that ERS, normalized for body weight, was lower in young pigs up to a pressure of $20 \mathrm{cmH}_{2} \mathrm{O}$. This was due to lower elastance of the chest wall in younger pigs, a finding in concurrence with observations in childhood [21, 22]. However, limited appropriateness of normalization of elastance to body weight might be a factor of importance for the differences observed.

The initial decline in $E$ RS and the first inflexion point observed at $5-10 \mathrm{cmH}_{2} \mathrm{O}$ in both the first and the second $P$ el, RS/ $V$ curves were caused by the chest wall rather than by the lung. Preliminary observations made with the present methodology in anaesthetized humans showed a similar finding [23]. As a falling ECW was constantly observed over the initial segment, a biological explanation rather than methodological errors is likely. Whatever the explanation might be, an LIP observed in a $P$ el, Rs $/ V$ curve should be regarded as a sign of lung recruitment only under circumstances when recruitment is known to be particularly important, such as in acute lung injury.

After the initial decline, ECW was nearly constant up to an inflation pressure of $40 \mathrm{cmH}_{2} \mathrm{O}$. Previous observations in mammals, which however cover only a part of the pressure range analysed here, are in line with a nearly constant ECW $[15,24,25]$. The nearly constant $E C W$ at inflation pressures above $10 \mathrm{cmH}_{2} \mathrm{O}$ implied that pressure variations in ERS mainly reflect properties of the lung [26, 27].

The increase in ECW, between the first and second recordings might represent a plastic rearrangement of thoracic structures. However, it cannot be excluded that changes within the lung are of some importance for ECW [28]. GRImBy et al. [24] showed that chest wall compliance is dependent on tidal volume in normal subjects under anaesthesia, being lower at low distending pressures. The present observations may reflect a similar phenomenon.

The higher ERS values and the lower volumes observed up to a distending pressure of $20 \mathrm{cmH}_{2} \mathrm{O}$ during the first compared to the second recording at ZEEP can be explained by a collapsed lung not sharing the gas insufflated. On the contrary, from $25-40 \mathrm{cmH}_{2} \mathrm{O}$, ERS was lower during the first recording while the volume deficit compared to the second recording was 
being recovered. According to the analyses of HICKLING [8] and Jonson et al. [9], this can be explained by a continuing recruitment of lung compartments. When a lung unit "pops open" it will suddenly increment its volume, which leads to a decrease in elastance. In the total lung this will appear as a continuous process during the whole process of recruitment. During the 1st insufflation at ZEEP, the recruitment process appeared to start at a tracheal pressure $20-25 \mathrm{cmH}_{2} \mathrm{O}$ and continued for the rest of the insufflation up to a pressure $\sim 40 \mathrm{cmH}_{2} \mathrm{O}$. Over this interval the transpulmonary pressure increased $\sim 13-22 \mathrm{cmH}_{2} \mathrm{O}$. According to the principle of interdependence between lung units described by MEAD et al. [29], the pressure over collapsed units in a partially aerated lung should be even higher. The critical opening pressure of collapsed lung units therefore extended well above $20 \mathrm{cmH}_{2} \mathrm{O}$. At normal surfactant function, such high opening pressures imply that the radius of the structures which open is very small [30]. Alveolar collapse rather than airway closure seems to be the main component of derecruitment as observed with computer tomography in anaesthetised and paralysed man [31].

A nearly constant $E$ L at high distending pressures during the second recording from ZEEP is remarkable, as the lung is known to get stiffer with high degrees of distension. A possible reason is that even during the second recording, recruitment occurred. This is concurrent with observations that recruitment may take several forceful and prolonged insufflations to be complete [32].

At PEEP, the smaller difference between the first and the second recordings, e.g. shown by lower values of $\triangle P$ el, $\mathrm{L}$, indicates that PEEP partially protects against lung collapse. This effect of PEEP has previously been observed, not only in acute lung injury and adult respiratory distress syndrome $[1,10,33-35]$, but also in healthy man [28]. However, even at PEEP, the second recording differed from the first in principle, as at ZEEP. This implied that the lung was partly collapsed even at PEEP and that a significant degree of recruitment occurred during the first recording. At PEEP, the second recording showed high and rising values of $E \mathrm{~L}$. This indicates that recruitment was not prominent. However, at the highest distending pressures applied, the $E \mathrm{~L}$ values tended to stabilize rather than to increase further. This may be an indication of some recruitment continuing even towards the end of the second recording at PEEP.

The tendency of the lung to collapse during ventilation at zero end-expiratory pressure and the effects of recruitment on pressure/volume curves observed in the pig in this study, seem particularly important. However, identical experiments have not been done in other species. Bernstein's early observations in rabbits suggest that the pig is not unique. Further studies are needed to clarify whether the lung of young and adult pigs differs from other species regarding lung collapse tendency.

\section{References}

1. Amato MBP, Barbas CSV, Medeiros DM, et al. Effect of a protective-ventilation strategy on mortality in the acute respiratory distress syndrome. $N$ Engl $\mathrm{J} \mathrm{Med}$ 1998; 338: 347-354.

2. Matamis D, Lemaire F, Harf A, Brun-Buisson C, Ansquer JC, Atlan G. Total respiratory pressurevolume curves in the adult respiratory distress syndrome. Chest 1984; 86: 58-66.

3. Ranieri VM, Giuliani R, Fiore $\mathrm{T}$, Dambrosio $\mathrm{M}$, Milic-Emili J. Volume-pressure curve of the respiratory system predicts effects of PEEP in ARDS: "Occlusion" versus "Constant flow" technique. Am J Respir Crit Care Med 1994; 149: 19-27.

4. Roupie E, Dambrosio M, Servillo G, et al. Titration of tidal volume and induced hypercapoia in acute respiratory distress syndrome. Am J Respir Crit Care Med 1995; 152: 121-128.

5. Servillo G, Svantesson C, Beydon L, et al. Pressurevolume curves in acute respiratory failure. "Automated low flow inflation" vs "Occlusion". Am J Respir Crit Care Med 1997; 155: 1629-1636.

6. Liu JM, De Robertis E, Blomquist S, Dahm PL, Svantesson C, Jonson B. Elastic pressure-volume curve of the respiratory system reveal a high tendency to lung collapse in young pigs. Int Care Med 1999; 25: 1140-1146.

7. Svantesson C, Sigurdsson S, Larsson A, Jonson B. Effects of recruitment of collapsed lung units on the elastic pressure-volume relationship healthy adults. Acta Anaesthesiol Scand 1998; 42: 1149-1156.

8. Hickling KG. The pressure-volume curve is greatly modified by recruitment. A mathematical model of ARDS lungs. Am J Respir Crit Care Med 1998; 158: 194-202.

9. Jonson B, Svantesson C. Elastic pressure-volume curves: what information do they convey? Thorax 1998; 54: 82-87.

10. Jonson B, Richard JC, Straus C, Mancebo J, Lemaire $\mathrm{F}$, Brochard L. Pressure-volume curves in acute lung injury. Evidence of recruitment above the lower inflection point. Am J Respir Crit Care Med 1999; 159: $1172-1178$.

11. Kempt E Xenotransplantation. J Intern Med 1996; 239: 287-297.

12. Svantesson C, Drefeldt B, Sigurdsson S, Larsson A, Brochard L, Jonson B. A single computer-controlled mechanical insufflation allows determination of the pressure-volume relationship of the respiratory system. J Clin Monit 1999; 15: 9-16.

13. Varéne P, Jacquemin C. Airways resistance: a new method of computation. In: Bonhuys A, ed. Airway dynamics - Physiology and Pharmacology. Springfield Thomas, 1970; pp. 99-108.

14. Bernstein L. The elastic pressure-volume curves of the lungs and thorax of the living rabbit. J Physiol 1957; 138: 473-487.

15. Mead J, Gaensler EA. Esophageal and pleural pressures in man, upright and supine. J Appl Physiol 1959; 14: 81-83.

16. van de Woestijue KP, Trop D, Clement J. Influence of the mediastinum on the measurement of esophageal pressure and lung compliance in man. Pflügers Arch 1971; 323: 323-341.

17. Bates JHT, Baconnier P, Milic-Emili J. A theoretical analysis of the interrupter technique for measuring
Acknowledgements. The authors wish to thank Björn Drefeldt for his generous and helpful technical assistance. 
respiratory mechanics. J Appl Physiol 1988; 64: 2204 2214.

18. Jonson B, Beydon L, Brauer K, Månsson C, Valind S, Grytzell H. Mechanics of respiratory system in healthy anaesthetised humans with emphasis on viscoelastic properties. J Appl Physiol 1993; 75: 132-140.

19. Similowski T, Levy P, Corbeil C, et al. Viscoelastic behavior of lung and chest wall in dogs determined by flow interruption. J Appl Physiol 1989; 67: 2219-2229.

20. Svantesson C, John J, Taskar V, Evander E, Jonson B. Respiratory mechanics in rabbits ventilated with different tidal volumes. Respir Physiol 1996; 106: 307316.

21. Fisher JT, Mortola JP. Statics of the respiratory system in newborn mammals. Respir Physiol 1980; 41: 155-172.

22. Papastamelos C, Panitch HB, England SA, Allen JL. Developmental changes in chest wall compliance in infancy and early childhood. J Appl Physiol 1995; 78: $179-184$.

23. Svantesson C, Sigurdsson S, Larson A, Jonson B. The contribution of the chest wall to the elastic pressurevolume curve of the total respiratory system. Int Care Med 1998; 24: S95.

24. Grimby G, Hedenstierna G, Lofstrom B. Chest wall mechanics during artificial ventilation. $J$ Appl Physiol 1975; 28: 576-580.

25. Mead J, Collier C. Relation of volume history of lungs to respiratory mechanics in anesthetised dogs. $J$ Appl Physiol 1959; 14: 669-678.

26. Katz JA, Zinn SE, Ozanne GM, Fairley HB. Pulmonary, chest wall, and lung thorax elastances in acute respiratory failure. Chest 1981; 80: 304-311.

27. Polese G, Rossi A, Appendini L, Brandi G, Bates
JHT, Brandolese R. J Appl Physiol 1991; 71: 24252433.

28. Tokics L, Hedenstierna G, Strandberg É, Brismar B, Lundquist $\mathrm{H}$. Lung collapse and gas exchange during general anaesthesia: effects of spontaneous breathing, muscle paralysis, and positive end-expiratory pressure. Anesthesiology 1987; 66: 157-167.

29. Mead J, Takishima T, Leith D. Stress distribution in lungs: a model of pulmonary elasticity. J Appl Physiol 1970; 28: 596-608.

30. Williams JV, Tierney DF, Parker HR. Surface forces in the lung, atelectasis, and transpulmonary pressure. J Appl Physiol 1966; 21: 819-827.

31. Hedenstierna G. Causes of gas exchange impairment during general anaesthesia. Eur J Anaesthesiol 1988; 5: 221-231.

32. Rothen HU, Sporre B, Engberg G, Wagenius G, Hedenstierna G. Re-expantion of atelectasis during general anaesthesia: a computed tomography study. $\mathrm{Br}$ J Anaesth 1993; 71: 788-795.

33. Cereda M, Foti G, Musch G, Sparacino ME, Pesenti A. Positive end-expiratory pressure prevents the loss of respiratory compliance during low tidal volume ventilation in acute lung injury patients. Chest 1996; 109: 480-485.

34. Ranieri VM, Eissa NT, Corbeil C, et al. Effects of positive end-expiratory pressure on alveolar recruitment and gas exchange in patients with the adult respiratory distress syndrome. Am Rev Respir Dis 1991; 144: 544-551.

35. Suter PM, Fairley HB, Isenberg MD. Effect of tidal volume and positive end-expiratory pressure on compliance during mechanical ventilation. Chest 1978; 73 : 158-162. 